Universidad de Panamá

Instituto de Estudios Nacionales
ISNN 1810-5491

Cuadernos Nacionales

$\mathrm{N}^{\circ} 27$, 54-80, julio-diciembre, 2020

\title{
Una aproximación a la participación electoral, abstencionismo y condiciones socioeconómicas en las elecciones 2004-2009- 2014 de la población panameña. Relaciones y controversias ${ }^{28}$
}

\author{
Lloyd Burrel, Tamara Martínez \\ Paredes, Virgilio Bazán y Yaritza Espinosa* \\ Universidad de Panamá \\ vbazan2010@gmail.com
}

\begin{abstract}
Resumen
La participación electoral en Panamá cumple con objetivos importantes en la democracia participativa. Estos objetivos van desde consolidar una formación o carrera política hasta legitimar al régimen y a los gobernantes escogidos. Existen diversos factores que intervienen y son determinantes en la participación electoral, entre ellos: los criterios demográficos y socioeconómicos. El análisis de estos factores es complejo, pero necesario para la salud de la democracia. La información electoral y socioeconómica oficial ocurridas entre los años 2004 y 2014, se ha utilizado para estudiar las relaciones y controversias, o no, del crecimiento económico sobre la participación electoral y el abstencionismo en el nivel nacional y provincial. Los resultados indican que el sistema político partidista panameño y el institucional emprenden estrategias y acciones tendientes a incrementar la participación y disminuir el abstencionismo. Por otra parte, la edad y el género no son impedimentos para una participación electoral representativa y se observa una alta relación entre crecimiento económico, participación y abstencionismo.
\end{abstract}

Palabras claves: participación política, participación electoral, abstencionismo, crecimiento económico, edad, género.

\begin{abstract}
Electoral participation in Panama meets important objectives in participatory democracy. These objectives range from forming or consolidating a political education or career to legitimizing the regime and the elected leaders. There are several factors
\end{abstract}

*Los autores son estudiantes que cursan la Maestría en Teorías y Métodos de Investigación Social, Programa dirigido por el Instituto de Estudios nacionales IDEN de la Universidad de Panamá.

28. Aprobado 24/12/2019 - Recibido 10/7/2020 
that intervene and are decisive in the electoral participation among them the demographic and socioeconomic criteria and the analysis of these factors is complex but necessary for the health of democracy. Using official electoral and socio-economic information that occurred between 2004 and 2014, the relationship or not of economic growth on electoral participation and abstention at the country and provincial levels is studied. The results indicate that the Panamanian political party system and the institutional one undertake strategies and actions tending to increase participation and reduce abstention. On the other hand, age and gender are not an impediment to high voter turnout and there is a high relation between economic growth, participation and abstention.

Keywords: political participation, electoral participation, abstentionism, economic growth, age, gender.

\section{Introducción}

La participación de la población en los actos democráticos cumple con objetivos importantes en la democracia participativa ${ }^{29}$. Estos objetivos van desde una perspectiva política como la de consolidar una formación o carrera política, desarrollar relaciones, tomar la decisión de ser figura elegible, hasta la participación electoral de legitimar al régimen y a los gobernantes escogidos. Es importante anotar que la participación electoral es una manifestación de la participación política. Esta última es mucho más compleja y más importante que la participación electoral, porque desde algunas perspectivas teóricas como la liberal y republicana puede evaluarse, o no, la salud democrática de un país (Nohlen, 2003). No se puede ver el fenómeno de la participación política, la participación electoral y el abstencionismo desligado, o de forma independiente, cada acción democrática tiene un objetivo diferente, aunque son interdependientes. Existen diversos factores que intervienen y son determinantes en la participación electoral, entre ellos: los criterios demográficos (edad, sexo, etc.), sociales y culturales (clase social, nivel educativo, área de residencia, adscripción étnica, religión, socialización familiar, etc), políticos (tipo de lección, interés por la política, militancia o identificación partidaria), jurídicos (obligatoriedad el voto, condiciones de inscripción y voto, etc). El análisis de la participación electoral es complejo, pero se llega a coincidir en que lo

29 La democracia participativa otorga a los ciudadanos una mayor, más activa y más directa capacidad de intervención e influencia en la toma de decisiones de carácter público y se asume como uno de sus objetivos que el ciudadano no limite su papel dentro del sistema democrático al ejercicio del sufragio, como ocurre en la democracia representativa, sino que asuma un rol protagónico, activo y propositivo dentro de la política, tanto a nivel comunitario, como regional y nacional. 
transversal es el grado de integración que tiene el individuo en la sociedad: cuanto más fuerte es, más probabilidades hay de participar en asuntos públicos y políticos, y asistir a votar. A la inversa; a menores vínculos con la sociedad: disminuyen las probabilidades de acudir a votar (Romero, 2015). En este artículo estudiaremos los factores que inciden en la participación electoral de la población panameña, para los comicios electorales en la elección de presidente, en los periodos 2004-2009 y 2015. Se ha partido de la hipótesis de que "el crecimiento económico determina la participación electoral y el abstencionismo en las tres (3) últimas elecciones presidenciales de 2004-2009- 2014”.

\section{METODOLOGÍA}

Estudiaremos los determinantes sociodemográficos de la participación electoral en las elecciones para presidente 2004-2009-2014 de la población panameña. El estudio fue realizado a partir de la recolección bibliográfica sobre el tema, el desarrollo de la teoría de estadodemocracia y poder de Max Weber, de la teoría política de Beatriz Franco y Javier Andrés Flores sobre "participación electoral: una discusión abierta" (2009) y los datos extraídos directamente de los registros electorales oficiales de los años 2004-2009-2014 y los datos oficiales de crecimiento económico de la Contraloría General de la República y del Ministerio de Economía y Finanzas.

Para este trabajo se construyó una matriz con datos agrupados, utilizando el programa estadístico spss versión 22. Para el documento escrito se elaboraron cinco tablas en formato excell. Las tres (3) primeras tablas describen la participación electoral con variables tales como: electores, votación y abstencionismo, edad y género; y las dos últimas con las variables: crecimiento económico, participación electoral y abstencionismo. Estas variables reflejan los niveles de correlación, o no, de la hipótesis planteada anteriormente. Se hicieron los análisis de las correlaciones bivariadas desde la teoría planteada. La variable dependiente es participación electoral y las variables independientes son: votación, abstencionismo, género, edad, crecimiento económico y pobreza. Se pretende correlacionar que para estos periodos electorales 2004-2009 y 2014, la participación electoral y abstencionismo de las elecciones presidenciales en los citados periodos, fueron determinados respectivamente por la variable crecimiento económico. 


\section{Desarrollo del tema}

\section{PODER-ESTADO-DEMOCRACIA-PARTICIPACIÓN ELECTORAL}

El abordaje de conceptos tan amplios como poder, estado democracia y participación electoral, nos adentra en una reflexión compleja, que trataremos de manera sucinta en este apartado. Todo esto, con base en la postura de filósofos, sociólogos y grandes pensadores como Marx, Engels y Shumpeter. Debemos iniciar señalando el planteamiento de este último, muy coincidente además con el de Weber, al afirmar que "la vida política dejaba poco margen para la participación directa" (Shumpeter 1942). Schumpeter considerada muy representativa la teoría y prácticas políticas de la segunda mitad del siglo XX. En esta obra intentaba definir la democracia por la fuente o los objetivos, llegó a concebirla como un simple método y, por consiguiente, como una problemática que "no puede ser un fin en sí mismo" (Shumpeter, 1942). Por eso, en su concepción, la democracia no tiene ningún significado ético-normativo, pues se destaca como método de organización colectiva, de competencia entre partidos políticos, considerado en la ciencia política oriental como una manifestación de la real democracia y participación política electoral. Su obra tiende a afirmar un concepto de la democracia como un medio para escoger a los encargados de adoptar las decisiones y fijar contrapesos para limitar sus excesos.

En este sentido, dentro del propio campo académico no marxista, se le ha otorgado mucha importancia a la percepción que tuvo Max Weber sobre los partidos políticos. Los concibió como las formas de socialización, que descansa en un reclutamiento formalmente libre, tienen como fin proporcionar poder a sus dirigentes dentro de una asociación y otorgar a sus miembros activos, por este medio, determinadas probabilidades, ideales o materiales (la realización de fines, objetivos o lograr ventajas personales o ambas cosas) (Weber, 1971). Uno de los fenómenos más importantes que se planteó Weber, sobre el devenir político de las sociedades de su tiempo, no era tanto la extensión del sufragio. Para él era central la creciente burocratización del aparato estatal y la creciente oligarquización de las organizaciones políticas. Por lo tanto, se constituía ya como un problema para la democracia moderna, mantener la burocracia bajo control.

En cuanto a los conceptos de Estado y Poder, que atañen a este análisis sobre la participación política, Marx y Engels lo interpretan como instrumento básico de dominación en la sociedad, entendido como elemento regulador. Esta tesis fue aceptada al parecer por muchos filósofos de la antigüedad, el medioevo, la modernidad y hasta la época contemporánea, asumiendo que por 
regla general "El Estado de la clase más poderosa y de la clase económicamente dominante que, con ayuda de él (estado), también se convierte en la clase políticamente dominante, adquiriendo con ellos nuevos medios para la represión y la explotación de la clase oprimida" (Engels, 1974).

Se reconoce la importancia de esta propuesta del marxismo acerca del Estado, su carácter de clase, en materia de estructura del Estado y de participación política en general. Señala que este, a su vez, se va articular alrededor de los intereses de la clase que tenga el control fundamental en la toma de decisiones políticas. Esta idea, más allá de los múltiples tejidos en las que se expresan las relaciones sociales, fue una de las traducciones prácticas más concretas e importantes de su concepción materialista de la historia. La politología occidental ha defendido tradicionalmente los modelos democrático-liberales al colocar a los estados capitalistas por encima de la sociedad, de la manera más neutra posible, como si este fuera capaz de atenuar las más profundas diferencias sociales y de clases.

El pensamiento político de Weber en el contexto histórico del surgimiento del capitalismo Industrial discrepa con el de Marx, para quien la lucha de clases constituía el motor de la economía y la sociedad. Por el contrario, Weber lo veía como un aspecto de la distribución de recursos y la lucha por el poder. Este autor denomina a los partidos políticos como "grupos de status" y le otorga igual importancia a los Estados Nacionales. En Weber el capitalismo industrial es distintivamente occidental en sus orígenes y con valores propios, por lo que le otorga un elemento importante en su análisis, la racionalidad.

En cuanto al concepto de Estado, democracia y participación, Weber destaca la democracia liberal, desde un punto de vista muy racional, mediante los procedimientos, por lo que en esta cultura la libertad de elegir es una especie de competencia entre valores. La democracia, en ese sentido, se convierte en un componente vital de los arreglos institucionales necesarios de una cultura política liberal. El problema de la verdadera participación política no es un asunto de la necesidad de un solo partido político para enfrentar, con mayor justicia y celeridad, los cambios sociales. Aun cuando ha tenido múltiples maneras de ser interpretada, e independientemente del régimen político en que se promulgue, esta se ha considerado, sobre todo, en dos sentidos esenciales: primero, como la capacidad de la población para sensibilizarse, con la información oficial que le brindan los gobiernos, a los distintos niveles y apoyar sus decisiones. En segundo lugar, como el proceso de intervención popular que transita por distintas etapas y niveles de formulación, planificación, ejecución y evaluación de políticas desde la base, para tomar las decisiones y repartir los beneficios. 
Finalmente, podemos decir que Weber, hizo importantes planteamientos que hoy día se mantienen vigentes, acerca de la democracia particularmente, cuestiones como la burocracia y el papel de la ciudadanía, en la exigencia o demanda hacia sus poderes estatales. Además, hoy se debate sobre el papel del Estado, por su parte, la ciencia política se reduce solo al estudio de las relaciones entre burócratas y los cargos electos para cumplir un mandato, entre otros. Se hizo preguntas importantes recogidas en su obra, La ética protestante y el espíritu del capitalismo, las cuales se deja a manera de reflexión: ¿Podemos escapar del control de los burócratas y tecnócratas en las sociedades complejas? ¿Se puede frenar de alguna manera la tendencia de los partidos a la oligarquía? ¿Vivimos en una partidocracia? Weber, Max, sociólogos alemanes (1864-1920).

\section{PARTICIPACIÓN POLÍtica Y PARTICIPACIÓN ELECTORAL - IMPORTANCIA-ENFOQUES}

Según Beatriz Franco Cuervo y Juan Andrés Flores en la Aproximación teórico conceptual de la participación electoral: una discusión aún abierta (2009), afirma que no se puede separar la participación política, de la participación electoral del abstencionismo y sus factores, es decir, son categorías con niveles de interrelación que son importantes estudiar.

\section{A. LA PARTICIPACIÓN POLÍTICA}

Se suele, con frecuencia, confundir la participación política con la electoral. Al finalizar las fiestas electorales, se suele decir que la participación fue alta o baja, sin detenerse a precisar que esta es una de las expresiones que se enmarcan dentro de la participación política, en este caso la electoral. La participación política se expresa en dos grandes corrientes de acción que se convierten en dos enfoques del concepto: uno que busca la reciprocidad y otro que se hace palpable a través de la competición, en la cual entra la participación electoral. El enfoque de reciprocidad consiste en que la participación política tiene que ver con la interacción entre los miembros de una comunidad política que busca la justicia entendida como, la distribución correcta de las existencias entre los ciudadanos acorde con los criterios públicos existentes. La participación política aquí no busca un beneficio particular, sino más bien el logro del bien común. La justicia desde este enfoque abre la posibilidad de que el ser humano hombre o mujer no se vea a sí mismo como un ser separado de la comunidad que lo rodea, sino interdependiente 
de esta, y por tanto como miembro de esa comunidad política, el individuo aprende a juzgar los asuntos del bien común, no bajo el paradigma estrecho del interés particular privado, sino utilizando el criterio público que consiste, básicamente, en pensar que su bienestar depende del bienestar colectivo. Con este enfoque, la participación política debe ser diferente a la forma de hacer política, la cual busca el mantenimiento de la comunidad por medio de diversas actividades: comunicación pública para resolver problemas, disputas y la cooperación entre los miembros individuales y grupales pertenecientes a la comunidad en cuestión. Se trata de una participación política con enfoque comunitario, de suerte que actuar con los demás miembros de la comunidad es un imperativo para promover los propósitos colectivos o compartidos. Estos buscan finalmente, incrementar el conocimiento político mediante la interacción y coordinación de los asuntos públicos, promover la realización personal y comunitaria y desarrollar algunas virtudes políticas como el sentido de cooperación y de la solidaridad.

Este enfoque comunitario se desprende de Aristóteles, el concepto de ciudadanía que estaba íntimamente ligado a los asuntos de la polis, así, por medio de su intervención en esos asuntos de la polis, el ciudadano formaba su identidad como sujeto público y político, con ello logra desarrollar las más importantes facultades humanas que son, para Aristóteles: el discurso y la razón. La participación era una afirmación de pertenencia a la polis, más que un ejercicio de los derechos y las obligaciones legales. El enfoque de competencia considera a la participación política como un instrumento de acción que busca influir a las élites gobernantes, con el fin de proteger ciertos derechos, maximizar ciertos intereses y asegurar legitimidad del régimen. Este enfoque de participación política afirma una perspectiva racional y pragmática, cuyo fin último busca influir u obtener el poder. Bajo esta visión, el interés particular prima sobre la construcción comunitaria y lógicamente la participación política se convierte en un instrumento para lograr ese fin. Por lo tanto, el proceso político es la formación, distribución y ejercicio del poder. El proceso de participación política de ese enfoque es el poder, según lo define Parson y Laswell: "como la participación en el proceso de tomas de decisiones, y autoridad como código institucionalizado que define los derechos de participación en el sistema político”.

La participación política debe ser entendida como toda actividad desarrollada por los miembros de una sociedad, tendiente a escoger a quienes gobiernan o influyen en las decisiones o políticas públicas específicas.

En palabras de McClosky, se puede definir la participación política como aquellas actividades voluntarias mediante las cuales los miembros de una sociedad intervienen en la selección de los gobernantes y, directa o indirectamente, en la formación de la política gubernamental. En consecuencia, se comprende que en la participación política se aglutinan diversas 
manifestaciones sociales, que intentan de varias formas, expresar puntos de vista y lograr con ello conductas o decisiones específicas por parte del gobierno o de una entidad estatal determinada. Es decir, los ciudadanos participan esencialmente con miras a expresar sus intereses, deseos y demandas privadas a las élites gobernantes. Este enfoque de la participación política es el predominante en nuestros días. Entre esas actividades o manifestaciones individuales y colectivas de participación política se destacan:

i) Las acciones ciudadanas en países en donde hay una fuerte tradición de movimientos sociales.

j) El reclamo de los derechos de petición.

k) Las movilizaciones sociales.

1) Participación electoral.

A partir de este conjunto de actividades realizables por parte de los miembros de una comunidad, se puede establecer una escala de participación política, utilizando la tipología de Milbrath:

1. Ciudadanos contendores, que se caracterizan por ocupar cargos públicos o partidistas, candidatos para un cargo, participar en la estrategia de campaña, contribuir con su tiempo en la campaña.

2. Es el ciudadano en transición que participa en reuniones políticas, hace aportes monetarios a las campañas, establece contactos con funcionarios públicos, partidistas.

3. Ciudadanos que realizan actividades de espectador, intentan influir en la decisión del voto de otros, ser miembro de un partido político.

4. Ciudadanos apáticos no votantes, desinteresados, desinformados, etc.

En vista de lo anterior es importante afirmar que la participación política como instrumento de acción se constituye en un fenómeno y por consiguiente en un concepto mucho más complejo y global que aquellos que se desprenden de este, como la participación electoral.

\section{B. LA PARTICIPACIÓN ELECTORAL-IMPORTANCIA-ENFOQUES}

La participación electoral constituye un aspecto parcial de la participación política; pero es la más masiva e importante. En los regímenes democráticos este tipo de participación se presenta como la alternativa más efectiva, directa y menos costosa para influir en la escogencia 
de los representantes y gobernantes y, en ciertos casos, en la ruta de algunas políticas públicas y modificaciones normativas.

Son tres las razones teóricas para considerar a la participación electoral la más importante.

1. De tipo sociológico y democrático argumenta dos principios:

- el primero de que es la más democrática porque pueden participar la mayoría de los ciudadanos.

- la segunda es la más igualitaria porque el voto de cada uno de los ciudadanos, que ejercen ese derecho y obligación, tiene el mismo valor formal que el de los demás. En otras palabras, no hay estratificación de los votos.

2. La segunda razón es de tipo político, porque la participación electoral es el canal directo y central de vinculación entre el electorado general, sus preferencias públicas y políticas y los elegidos, tanto ejecutivos como legislativos. Los votos que depositan los ciudadanos, que finalmente conforman la participación electoral, legitiman a los escogidos en el proceso y, por ende, se establecen vínculos entre nosotros.

3. Esta razón es de tipo sistémico y aduce que la vinculación que se da entre el electorado escogido está conformada, de un lado, por una entrada (imput), entendida como la legitimación del proceso electoral llevado a cabo, a través del cual toda la sociedad queda ligada y relacionada, y una salida o resultado (output) que les atañe y afecta a las políticas públicas implementadas por los escogidos.

Como todo fenómeno social la participación electoral tiene distintas perspectivas, que se traducen en enfoques teóricos conceptuales de tipo dicotómico (división del objeto) y disyuntivo (2 o más opciones). Así la participación electoral se puede abordar desde la teoría de la participación liberal y republicana, como también desde las perspectivas de participaciones intrínsecas y extrínsecas y, finalmente, desde la visión de la participación como derecho y como función. La Teoría de la participación liberal, es menos exigente, la abstención, no es un problema real en la democracia. Esa diferencia entre los abstencionistas y los votantes es muestra clara de la libertad que debe existir en estos regímenes. Pero hay que diferenciar entre voto activo y voto pasivo. En la medida en que no es viable transformar a todos los ciudadanos en personas activas electoralmente, así mismo no son necesarios altos niveles de participación 
activa, ni son precondición para consolidar la democracia, ni para ratificar cualitativamente mejoras a un régimen de este tipo. Esta visión liberal hace compatible el abstencionismo con el régimen democrático. También plantea que solo una porción de la población respectiva sea políticamente activa. Nicolás Gómez Dávila, insiste en que el porcentaje de electores, que se abstiene de votar, mide el grado de libertad concreta en una democracia, en la cual la libertad es ficticia, o es amenazada, el porcentaje tiende a cero.

La teoría de la participación republicana, le da mucha importancia a la participación electoral. Considera que una participación activa es precondición para consolidar el régimen político existente, en consecuencia, cuenta más participación haya en los procesos, mayor nivel democrático, en términos cualitativos, va a existir. Por lo tanto, el abstencionismo y el ausentismo son problemas graves de las democracias y plantean soluciones a la necesidad de mejorar la educación cívica, las prácticas pedagógicas para formar ciudadanos en las virtudes republicanas, para que se le dé la importancia merecida a la participación política electoral y, de esa forma, consolidar cualitativamente el régimen democrático respectivo.

En relación con la perspectiva intrínseca, la participación electoral es vista en como un valor fundamental de la democracia. El hecho de la acción de participar es más que suficiente, se convierte en el sentido mismo de la participación. Lo que importa es que la participación electoral se convierta en el fin mismo y no en el medio para lograr un determinado efecto o meta, y ese fin, es precisamente la autorrealización en el proceso de la acción democrática conjunta. Intrínsecamente en las elecciones no importa la calidad de los candidatos y de los que, finalmente, resulten elegidos; como tampoco la percepción que tiene el ciudadano sobre su capacidad real de influir en las decisiones políticas. De hecho, lo que realmente importa es el acto de participar, que se constituye por sí solo en un evento positivo para el sistema político. Desde esta perspectiva, la participación electoral por sí sola es un valor democrático y un fin en sí mismo.

La perspectiva extrínseca, es considerada el medio para lograr un fin, escoger a los gobernantes y legitimar al régimen. La perspectiva extrínseca sí le da valor al efecto de la participación electoral, sin interesarle exclusivamente el acto de participar. Lo importante es que se cumplan con los objetivos fundamentales de la democracia representativa, que en palabras de Fiallos son, por una parte, la determinación cualitativa y la medición cuantitativa de la voluntad del pueblo en cuanto a la elección de funcionarios y programas y, por la otra, la de conferir legitimidad a los gobernantes y sus programas y así facilitar la gobernabilidad y la paz social sostenible. La visión de la participación como derecho y como función: como derecho la participación electoral es una posibilidad de los ciudadanos y tiene opción a negarse a utilizarla, 
es el ciudadano quien tiene la facultad de decidir si participa o no. La participación como función es una característica del sistema y, por tanto, adquiere un carácter de compromiso y deber ciudadano pasando a un segundo plano el sentido del sufragio como derecho.

\section{EL FENÓMENO DEL ABSTENCIONISMO}

Según Beatriz Franco Cuervo y Javier Andrés Flores en Aproximación teórica conceptual de la participación electoral: una discusión aún abierta, plantean una definición de abstencionismo que se diferencia de otras manifestaciones por dos causas, una voluntaria y la otra involuntaria. El abstencionismos se puede definir de una forma negativa como la no participación en el acto de votar de quienes tienen derecho a ello. (Flores, 2009). El abstencionismo es un indicador de la participacion electoral, es el porcentaje de los que no votaron versus de los que sí votaron, sin explicar las causas de la no participación.

En las democracias actuales, el abstencionismo puede ser un problema o no, visto desde la perspectiva de la participación republicana y liberal. Desde la participación republicana es un problema porque puede evidenciar que no hay participación activa; factor fundamental para consolidar y legitimar el régimen. Tanto es así, que implementan acciones dirigidas a mejorar la educación cívica para la formación del ciudadano con virtudes republicanas que enfatice la importancia de la participación político electoral para consolidar el régimen democrático. Desde la participación liberal el abstencionismo es una oportunidad de demostrar las libertades democráticas y es compatible con el régimen democrático, en la medida en que se confirma la libertad, libre pensamiento y decisión, como también es la reacción de inconformidad al resultado de gobiernos deficientes. Existe una diferencia fundamental del término abstencionismo electoral, es la causa voluntaria e involuntaria.

Cuando el elector no vota, pero es consciente y lo hace voluntariamente se denomina abstencionismo electoral voluntario, esta es la manera en que él y la votante no ejercen su derecho al sufragio, pese a estar habilitados para hacerlo. Hay dos grupos de razones para esta conducta electoral y se conoce como abstencionismo electoral voluntario:

1. Actitud pasiva como expresión de su desobediencia cívica. Se denomina abstencionismo electoral político consciente. Realiza acciones tales como:

- Rechazar el sistema político existente.

- Objetar el acto electoral propiamente dicho.

- No se siente identificado con ninguno de los candidatos y programas que se presentan. 
- Quiere sentar una posición con respecto al mal desempeño del gobierno y cuando hay posibilidades de reelección.

2. Actitud indiferente ante el proceso electoral y la política misma. No votan por la pereza, la ley del mínimo esfuerzo. A este fenómeno se le denomina abstencionismo apático.

También es abstencionismo electoral cuando las causas son involuntarias y se denomina ausentismo o abstencionismo electoral técnico. Esta realidad, se da cuando el elector quiere ejercer sus derecho al voto y no puede hacerlo por causas técnicas, coyunturales que limitan su derecho. Las causas de este fenómeno pueden ser:

1. Lejanía de los puestos de votación.

2. Ausencia del voto en el extranjero.

3. Limitaciones producidos por desastres naturales.

4. Intimidación por grupos al margen de la ley.

5. Mal estado de salud.

6. Limitaciones en cuanto a la infraestructura y al número de mesa de votación en centros carcelarios, facilidades para la votación de personas discapacitadas, entre otras.

\section{LA PARTICIPACIÓN ELECTORAL EN LATINOAMÉRICA Y PANAMÁ}

A partir de las transformaciones democráticas implementadas por diversos países latinoamericanos, la mirada a la participación electoral nos dice que existe un solo país en América Latina, en el cual la participación electoral es tradicionalmente baja: Colombia: en este país la participación oscila entre un 55\% y un 32\%, y alcanzó su máximo por encima del 50\% a principio de los años 90, cuando con la nueva constitución de 1991 fue posible integrar a un sector de la guerrilla. En el transcurso de los últimos años, la participación electoral estuvo bajando continuamente, en el Salvador, Guatemala y la República Dominicana tocando el 50\% de participación electoral. Venezuela durante los años 90 su participación electoral fue crítica; pero se incrementó y alcanzó un 56.5\% hacia el año 2000. La participación electoral sigue siendo alta, por encima del 70\%, aunque con ligera tendencia, la baja en Argentina, Bolivia, Brasil, Chile, Costa Rica, Nicaragua y Panamá. Es tradicionalmente alta en Uruguay, donde subió incluso desde la democratización en cuatro puntos por encima del 90\%. Sube también en Perú, en Paraguay del 54\% en 1989 al 80\% en 1998 y en México durante los años 1990, llegando allí a $63 \%$. 
En el caso de Panamá, la participación electoral es alta, lo demuestran los datos del Tribunal Electoral de las últimas cuatro (4) elecciones: la de 1999 fue de 1,336,172; la de 2004 fue de 1,471,705; la de 2009 fue de 1,634,594 y la de 2014 fue de 1,885,571. Entre cada periodo se incrementó en un promedio de 200,000 personas. Según estos datos simples el abstencionismo en nuestro país no es un problema. A pesar de esta realidad, se hace necesaria la observación de la participación electoral en Panamá, lo que permitirá generar acciones y estrategias para fortalecer la democracia participativa.

\section{FACTORES SOCIODEMOGRÁFICOS $\quad$ Y SOCIOLÓGICOS EN LA PARTICIPACIÓN ELECTORAL}

En este apartado estudiaremos los factores demográficos y sociológicos que pueden explicar la participación electoral de una población determinada. Sobre la base de estos factores y los datos demográficos electorales y socioeconómicos oficiales organizados, explicaremos la participación electoral de la población panameña de los periodos 2004-2014. Es importante reafirmar, como se señaló en la introducción de este artículo, que la participación política y electoral se vincula con el grado de integración que tienen los individuos y los grupos sociales en la sociedad. Cuanto más fuerte es la integración hay una gran probabilidad de participación masiva, por el contrario, sería a menor integración, disminuye la participación en los asuntos políticos y electorales.

\section{FACTORES DEMOGRÁFICOS}

Desde la perspectiva demográfica, la participación electoral depende de factores tales como la edad, el género, el nivel de vida, el área de residencia, la aceptación de las políticas públicas, las facilidades institucionales electorales, la cultura y la historia. La participación electoral según la edad es baja en los años juveniles, se incrementa en la edad madura y disminuye en la tercera edad. Según el género la participación electoral en un principio fue mayor en los hombres que en las mujeres, a medida que la mujer eleva su nivel de vida económica y educativa, aumenta la participación política y electoral. Los sectores con mejores niveles de vida y educación resultan ser los más participativos política y electoralmente. El área residencial es también un factor fundamental, mientras que en la ciudad los sectores poblacionales tienen mayor accesibilidad a los servicios políticos y electorales. En el área rural e indígena hay mayores problemas al acceder a estos servicios de inscripción y de votar. La 
participación electoral también depende del ambiente político que se esté desarrollando. Eventos electorales con muchos conflictos provocan disminución de la participación, mientras que la polarización genera masiva participación electoral. Otros factores institucionales como las facilidades de inscripción, la obligatoriedad o no votar, influyen en la participación masiva o no masiva.

Finalmente, la cultura e historia política de los pueblos inciden en la participación electoral. Mientras que la participación electoral es mayor en aquellos países que exaltan, llenan de solemnidad y tratan con mucho respeto y seriedad lo político y lo electoral, la participación electoral es baja en países en donde la historia política ha sido marcada negativamente con fraudes, poco pluralista y con evidente clientelismo.

\section{FACTORES SOCIOLÓGICOS}

El estudio sobre la participación electoral en América Central del año 2015 hace énfasis en que los factores sociológicos tales como: desarrollo humano, nivel de integración en la sociedad, institucionales, administrativos, ambientes sociales violentos, conflictivos y en donde se caracteriza la impunidad, inciden en la participación electoral.Hay una significativa vinculación entre desarrollo humano y participación electoral. Altos niveles de desarrollo humano, generan masiva participación electoral; bajos niveles de educación, salud, ingresos, se correlacionan con la participación y la abstención.

La participación electoral se incrementa cuando hay altos niveles de integración en la sociedad: altos grados educativos, alta inserción laboral, integración con las organizaciones sociales, libertad de expresión, fluido acceso a los medios de comunicación e interés por la política. Habrá baja participación electoral, si hay gran cantidad de gente marginada, excluida y en desigualdad. Como factores institucionales y administrativos que facilitan o limitan la participación electoral se encuentran las decisiones administrativas o jurisdiccionales electorales. La distribución de las mesas limita o facilitan la participación electoral, cuando no se da una descentralización en todo el territorio y se apuesta a centralizar las mesas con argumentos no justificables, la participación se ve disminuida.

La eficiencia de los servicios electorales es otra causa de facilidad o limitación de la participación electoral. Cuando se es eficiente en la producción y distribución del documento de identidad personal, se da una marcada participación electoral, restringir el acceso a la cédula de identidad personal, impide el sufragio de las grandes mayorías. 
En fin, las sociedades sumergidas en la violencia social producto del crimen organizado, narcotráfico, la impunidad y la pérdida de confianza en las instituciones, causan que la participación electoral se vea limitada por los secuestros, asaltos y asesinatos de candidatos y electores.

\section{FACTORES QUE INCIDEN EN LA PARTICIPACIÓN ELECTORAL EN PANAMÁ}

En este apartado se describirá y se realizará correlaciones de la participación electoral de la población panameña a partir de los periodos electorales presidenciales de los años 2004-20092014. Para la citada descripción y correlación utilizaremos los periodos (elecciones) citados, las variables electoras (padrón), votación (participación), abstencionismo, sexo, edad, crecimiento económico.

\begin{tabular}{|l|l|l|l|}
\hline \multicolumn{4}{|l|}{ Tabla $\mathrm{N}^{\circ} 1$} \\
\hline Comportamiento de la participación electoral en Panamá \\
\hline Variable & Elecciones 2004 & Elecciones 2009 & Elecciones 2014 \\
\hline Electores & $\mathbf{1 , 9 9 9 , 5 5 3}$ & $\mathbf{2 , 2 1 1 , 2 6 1}$ & $\mathbf{2 , 4 5 7 , 4 0 1}$ \\
\hline Votaron & $\mathbf{7 6 , 9 \%}$ & $\mathbf{7 4 , 0 \%}$ & $\mathbf{7 6 , 8 \%}$ \\
\hline Abstencionismo & $\mathbf{2 3 , 1 \%}$ & $\mathbf{2 6 , 0 \%}$ & $\mathbf{2 3 , 2 \%}$ \\
\hline
\end{tabular}

Fuente: Tribunal Electoral, Dirección Nacional de Organización Electoral, Departamento de Estadísticas Electorales. Cuadro No. 1 correspondiente a los centros de votación, mesas escrutadas, padrón electoral, votos emitidos, participación electoral, abstención, votos válidos, votos en blanco y votos nulos en la república, según provincia, comarca y circuito electoral: elecciones populares para presidente del 2 de mayo de 2004, 3 de mayo de 2009 y 4 de mayo de 2014. Cuadro elaboración propia del grupo de investigadores.

La tabla $\mathrm{N}^{\mathrm{o}} 1$ nos da una lectura que refleja un incremento de los electores en el padrón final en cada periodo 2004, 2009 y 2014. La lectura de la votación nos indica que disminuyó en el 2009 a un $2 \%$ y se incrementó a un $2 \%$ en el 2014. En cuanto al abstencionismo se incrementa a un $3 \%$ en el 2009 y disminuye a un $3 \%$ en el 2014. Una aproximación a la respuesta de esta lectura se puede describir con hechos y eventos sucedidos en el sistema político y en el sistema institucional electoral de Panamá en los periodos 2004-2009-2014.

Desde la perspectiva del sistema político panameño, según (Harry Brown Araúz) el politólogo panameño, los hechos más relevantes que pueden explicar la lectura del incremento de los electores, la subida y disminución de la votación y el bajo abstencionismo se pueden concentrar en veinte (20) factores que se han identificado desde la transición hasta la democracia respectivamente (Araúz, 2018), en los periodos 2004-2009-2014, son los siguientes:

1. El sistema político garantizó la autonomía institucional y financiera del Tribunal Electoral como garante de la realización de elecciones transparentes. 
2. La designación de los tres (3) nuevos magistrados han estado a cargo de cada órgano del estado.

3. La composición del Tribunal Electoral refleja la correlación de fuerzas partidistas del país.

4. El Tribunal Electoral legitima sus decisiones consultando a las partes interesadas.

5. Los procesos que se realizaron durante el periodo que se analiza, cinco (5) elecciones generales, se pueden caracterizar respectivamente, como de eficientes y con índices de participación medios altos y altos a media baja. Cuando los temas, en los citados procesos de elecciones generales y consultas populares, han sido de fundamental interés de los partidos políticos, la participación es alta; pero cuando no han sido de interés, la participación ha sido media y baja.

6. La proliferación de los circuitos plurinominales.

7. Una política de financiamiento público y privado opaca e ilimitada, lo que dilata la incorporación de nuevos actores a la contienda política, sanciona duramente a los partidos pequeños hasta hacerlos claudicar, lo que disminuye el pluralismo y generan alianzas bipolares en la elección presidencial. Esto da como resultado una representación incompleta de la sociedad.

8. Un sistema político que genera inequidad entre los competidores, propicia una representación de baja calidad y es excluyente específicamente de otras corrientes de pensamiento.

9. El clientelismo político que condiciona la conciencia política del electorado en su derecho a inscribirse en algún partido político y al ejercicio del sufragio con el objetivo de obtener empleo y beneficios personales. 
10. El crecimiento económico y del PIB, la reducción del desempleo, el incremento del presupuesto del estado y el destino de un gran porcentaje hacia la inversión en infraestructuras, se ensombrece con la alta tasa de informalidad, pobreza y desigualdad.

11. El conservadurismo que ha llevado a que Panamá sea el segundo país más intolerante en temas políticos, y sociales (educación sexual, derechos de los LGTBI), logrando inclusive a determinar la elección presidencial durante los periodos que se describen.

12. El fin del sistema de coaliciones polarizado en los dos más grandes partidos por el sistema de convivencia de partidos medianos pequeños y candidatos presidenciales independientes.

13. La fragmentación y concentración del voto. La fragmentación se da cuando los votos del electorado se han concentrado en una oferta electoral limitada, o por el contrario, el voto se reparte entre muchas opciones. La concentración del voto se da cuando se vota más para alguna de las dos elecciones presidenciales o de diputados. Para el año 2009 disminuyó en un $2 \%$ la concentración del voto para presidente en comparación con el año 2004 y 2014. El voto 2009 se concentra hacia la elección de diputados, en consecuencia, el sistema político partidista unió esfuerzos para lograr la mayoría de los escaños en la Asamblea Nacional.

14. El número efectivo de partidos, es decir, la evolución del sistema de partidos. El índice de partidos presidenciales para el año 2014 fue de 4.0, de 1994 a 2004 fue de 3.32 y en el año 2009 se incrementó a 3.77 partidos importantes.

15. La volatilidad electoral que estima la cantidad de votantes que modifican su opción de voto de unas elecciones a otras. Mientras que para los años 2004 a 2009 las elecciones presidenciales de Panamá obtuvieron su mayor índice de volatilidad del sistema de partidos panameños que fue de 43, para el periodo 2009-2014 esta volatilidad cayó a 20. Esta caída se debe a que en Panamá y la región se vivió en estos periodos un ambiente de sistemas políticos excluyentes.

16. El modo de elección presidencial que es por medio de mayoría simple, sin la opción de segunda vuelta hasta 2014 y paralelamente con las legislativas por medio de una forma 
de lección diferente: por circunscripción uninominal y plurinominal. Este sistema electoral simple y por circunscripción uninominal y plurinominal en paralelo causa consecuencias reductoras sobre el sistema de partidos. Se trata entonces de la creación de circunscripciones electorales uninominales y plurinominales con proporciones divergentes entre votantes y representantes que responden a los intereses políticos partidistas.

17. La disponibilidad de votar por el electorado de distintos partidos, candidatos y evento electoral. Para el periodo 2014 fue la más alta en comparación con el año 2009 en el ámbito de distintos partidos y evento electoral; pero baja e irregular en los candidatos. Sí hubo mayor disponibilidad para votar con distintos partidos dentro del mismo evento electoral, es decir, a votar por partidos distintos en la elección presidencial y en las legislativas.

18. Otra importante explicación se da en la oferta electoral femenina. Para el año 2014 se logró un $18.3 \%$ de escaños en la asamblea por parte de las mujeres, el porcentaje más alto desde la transición a la democracia; pero lejos del 50\% de población de las mujeres y del $52.3 \%$ de los votos emitidos por las mujeres en las últimas elecciones. Esta lectura nos indica que el electorado panameño desde el género no está muy dispuesto a votar por distintas opciones.

19. Otra importante explicación al comportamiento de la participación electoral 2004-20092014, se da en la posición ideológica de los partidos y del votante. Para las elecciones 2014, esta lectura es expresada en que las alternativas políticas no fueron muy diferentes. De forma muy general se polariza la mayoría de los votantes entre posición ideológica de los partidos de centro y centro derecha.

20. Para finalizar la conducta de participación electoral de los citados periodos desde el sistema de partidos se puede explicar producto de la alternancia y vulnerabilidad del partido de gobierno. Para los periodos que se describen siempre ha ganado la oposición y se da la alternancia, es decir, que un mismo partido no repite en la elección presidencial. El gobierno de turno, es susceptible de ser criticado por la oposición a tal punto que esta realidad incide en la conducta del votante. 
Desde otra perspectiva para describir el comportamiento electoral de la tabla $\mathrm{N}^{\circ}$, es necesario remitirse a los antecedentes históricos, políticos y aspiracionales de los ciudadanos o grupos de poder cualquier que sea su matiz ideológico y político regional o local. Para describir el comportamiento electoral de la tabla $\mathrm{N}^{\circ} 1$, es necesario remitirse a los antecedentes históricos, políticos y aspiracionales de los ciudadanos o grupos de poder cualquiera que sea su matiz ideológico, político, regional o local. Esto tiene que ver con la salida de los gobiernos militares y de lo que politólogos han llamado como el retorno a la democracia, a esto hace referencia la OEA en los siguientes términos:

Después de años de inestabilidad y dictaduras, el retorno de elecciones libres y justas en América Latina generó expectativas sobre una posible ola regional de entusiasmo con los procesos democráticos. Varias generaciones de electores que habían perdido el derecho a votar, pudieron regresar a las urnas. Quienes nacieron durante los gobiernos de facto, pudieron expresar sus preferencias políticas por primera vez, y quienes nacieron en los primeros años de esta nueva época, pudieron imaginar con toda libertad el día en que pudieran votar ( Secretaría General de la Organización de los Estados Americanos (SG/OEA) y la Universidad Laval., 2015).

En el caso panameño esta premisa se podría sostener en la evidente constante de participación electoral que se mantiene superando el $70 \%$ después del periodo militar. Según el informe del Estado de la Región 2016: "Guatemala en la primera ronda de 2015 y Panamá en 2009 y 2014, son los países con los mayores porcentajes de asistencia a las urnas, más del 70\%”. (Estado de la Región , 2016). El segundo componente de la triada corresponde a los esfuerzos formales provenientes de la entidad rectora en materia electoral, puesto que la agenda del Tribunal Electoral de Panamá a partir de los años noventa se concentra en anular cualquier sospecha de fraude electoral, entre otros esfuerzos destaca el programa de Educación Cívica Electoral, hasta la fecha se ha fortalecido mediante convenios con el Ministerio de Educación por lo que se evidencia el alcance del mismo en las escuelas primarias y secundarias del país; buscando, entre otros resultados, motivar la participación de los jóvenes en el proceso electoral y en el ejercicio del sufragio.

La inclusión de figuras como el voto en el extranjero, voto en hospitales, hogares de atención al adulto mayor y centro penitenciarios, con perspectiva a las elecciones del 2019 se incluye la figura del voto adelantado para presidente de la República y podrán ejercerlo los miembros de la Policía Nacional de Panamá, funcionarios del Tribunal Electoral, Fiscalía Electoral, Sistema Nacional de Protección Civil, esto permite que este sector de la población participe en el evento electoral y así se evita el aumento de panameños que no ejercen el voto en cada elección, esto se 
complementa con el alcance del Tribunal Electoral en el territorio nacional. El último elemento que se podría considerar que aporta a la alta participación electoral es el estado de bienestar. Con respecto a la situación económica del país hasta las elecciones del 2014, ya que según el Latinobarómetro se da una relación directa entre bienes económico y confianza en las instituciones democráticas y lo plantea así: "La economía parece importar para los grados de confianza en las instituciones de la democracia cuando esta afecta de manera sustantiva el bienestar de una parte importante de la población como fue en la crisis asiática" (Corporación Latinobarómetro , 2017). Esto muestra como en Panamá valdría pensar que la estabilidad económica del país contribuye en la estabilidad y el proceso electoral, sobre todo, en la intensión y ejercicio del sufragio. Una vez agotadas las tres aproximaciones a la cuales podría acreditarse la sostenibilidad de la participación electoral queda preguntarse ¿Qué pasa con el abstencionismo en Panamá?

En el 2017 se realizó en Panamá el Encuentro de Estudios Democráticos, en cuya relatoría se realiza una observación interesante a modo prospectiva y es la siguiente:

Para efectos de registro, dejamos constancia que se identificó el abstencionismo como un problema en el sistema electoral. A falta de mayores consideraciones, los porcentajes altos y sostenidos de participación electoral en el período pos invasión, inciden en que no lo incluyamos como problema de investigación. También es interesante plantear la posible paradoja existente en la relación entre los enunciados "crisis de la política", "crisis del sistema de partidos", "crisis de partidos" y "desafección a la política", todos estos elementos contrastados con la estabilidad política y la alta participación electoral experimentada durante el mismo período, podría asumirse que se encuentra en la vía electoral un mecanismos de participación activo y eficiente pero en el tiempo ineficaz, por lo cual la abstención podría reflejarse en los próximos procesos electorales como respuesta a un fenómeno de cúmulo de aspiraciones ciudadanas no resueltas hasta la actualidad. (Tribunal Electoral de Panamá, 2018).

El sistema político panameño en general, pero el electoral en particular, comienza a mostrar interesantes asimetrías con hechos históricos, sociales, económicos y culturales que requieren ser estudiados. Por ejemplo podríamos cerrar esta sección preguntado ¿Qué implicaciones tiene o no el clientelismo para los altos índices de participación electoral en Panamá? ¿Podría agotarse la necesidad aspiracional y provocar abstencionismo en una generación de ciudadanos, cuyos intereses y expectativas de las democracias se dinamizan en realidades e intereses distintos a los de los años ochenta y noventa? 


\begin{tabular}{|l|l|l|l|}
\hline \multicolumn{4}{|l|}{ Tabla N² } \\
\hline Porcentaje de la participación electoral según género \\
\hline Género & Elecciones 2004 & Elecciones 2009 & Elecciones 2014 \\
\hline Femenino & $\mathbf{5 0 . 9 7 \%}$ & $\mathbf{5 1 . 9 8 \%}$ & $\mathbf{5 2 . 7 7 \%}$ \\
\hline Masculino & $\mathbf{4 9 . 0 3 \%}$ & $\mathbf{4 0 . 0 2 \%}$ & $\mathbf{4 7 . 7 3 \%}$ \\
\hline Total & $\mathbf{1 0 0 \%}$ & $\mathbf{1 0 0 \%}$ & $\mathbf{1 0 0 \%}$ \\
\hline
\end{tabular}

Fuente: Tribunal Electoral, Dirección Nacional de Organización Electoral, Departamento de Estadísticas Electorales. Cuadro No. 1 correspondiente a la participación electoral por género y grupo de edad, según provincia y circuito electoral en las elecciones generales del 2 de mayo de 2004, 3 de mayo de 2009 y el 4 de mayo de 2014. Cuadro elaboración propia del grupo de investigadores.

La tabla $\mathrm{N}^{\circ}$ 2, nos refleja que mientras la participación de la mujer en los comicios electorales 2004-2009 y 2014 para presidente se incrementa en un 1\%, la participación electoral del hombre disminuye en un 9\% para el 2009 y se incrementa en un 7\% para el año 2014.

La Organización para la Cooperación y el Desarrollo Económico ha destacado la desigualdad de género, considerándolo un asunto transversal que requiere ser evaluado a lo largo de cada una de las dimensiones del bienestar. Las mujeres tienden a mostrar peores resultados en la mayoría de los ámbitos de bienestar como: empleo, vulnerabilidad y evaluación de la vida. En especial, tienen más probabilidades de estar fuera del mercado laboral, así como un mayor riesgo de desempleo en comparación con los hombres. Por el contrario, las mujeres tienden a mostrar mejores resultados en educación, salud y relaciones sociales. (OCDE, 2017. De allí, que consideremos que muestran una alta participación electoral, en cuanto a ejercer el derecho ciudadano a votar por un Presidente, lo cual toman como una oportunidad para mejorar su calidad de vida. Panamá también busca cumplir con la obligación de tomar medidas para eliminar la discriminación contra las mujeres, en lo referente a la participación política, mediante la adopción de una serie de reformas legislativas. Estas conllevan a que, en la actualidad, el artículo 303 del Código Electoral disponga que se debe garantizar que, como mínimo, el 50\% de las candidaturas sean para mujeres.

En el período 1999-2004 surgió un posible foco de inestabilidad, ya que la volatilidad presidencial aumentó sensiblemente hasta ser de 38.2\%. Este aumento se debió al repunte de algunos partidos políticos y la merma de los apoyos electorales presidenciales del Partido Arnulfista. Según el Politólogo Harry Brown, no será al menos hasta las elecciones de 2009 que se comprobará si esta situación respondió a un desvío momentáneo o fue el inicio de la reconfiguración del sistema de partidos panameños. (Brown, 2009). Los más recientes comicios tuvieron lugar el 4 de mayo de 2014. El 77\% de los ciudadanos habilitados para votar, sufragó en la elección presidencial (Tribunal Electoral, 2014). Este porcentaje de participación supera ligeramente el promedio del período democrático (76\%). El clientelismo político, financiado con recursos estatales 
y particulares, es un motor importante de la participación electoral y contribuye a explicar el fenómeno de la concurrencia a las urnas en Panamá.

\begin{tabular}{|l|l|l|l|}
\hline \multicolumn{4}{|l|}{ Tabla No3 } \\
\hline \multicolumn{4}{|l|}{ Porcentaje de la participación electoral según edad } \\
\hline & Elecciones 2004 & Elecciones 2009 & Elecciones 2014 \\
\hline Jóvenes & $\mathbf{5 5 . 6 9 \%}$ & 52.15 & 49.27 \\
\hline Maduros & $\mathbf{3 1 . 0 4 \%}$ & 32.91 & $\mathbf{3 4 . 0 9}$ \\
\hline $\begin{array}{l}\text { Adultos } \\
\text { mayores }\end{array}$ & $13.27 \%$ & 14.94 & 16.64 \\
\hline Total & $100 \%$ & $100 \%$ & $100 \%$ \\
\hline
\end{tabular}

Fuente: Tribunal Electoral, Dirección Nacional de Organización Electoral, Departamento de Estadísticas Electorales. Cuadro No. 1 correspondiente a la participación electoral por género y grupo de edad, según provincia y circuito electoral en las elecciones generales del 2 de mayo de 2004, 3 de mayo de 2009 y el 4 de mayo de 2014. Cuadro elaboración propia del grupo de investigadores.

La tabla $\mathrm{N}^{\circ} 3$, nos refleja lo siguiente:

- La juventud es la que más vota para cada elección, seguida de las personas maduras y los que menos votan son los adultos mayores.

- La votación de los jóvenes bajo un 3\% para el año 2009 y un 3\% para el 2014 con respecto al año 2004.

- La votación de los maduros se incrementa en un $2 \%$ para el año 2009 y un $2 \%$ también para el año 2014. También se incrementa en un 1\% la votación de los adultos mayores para el año 2009 y un $2 \%$ para el año 2014.

Esta lectura de la votación de los jóvenes que más vota para cada elección es contraproducente con lo descrito en la conducta demográfica electoral que dicta que según la edad, la votación es baja en los años juveniles, se incrementa en la edad madura y disminuye en la tercera edad. En la realidad panameña es todo lo contrario; para cada elección los que más votan son los jóvenes seguida de los maduros y por último, los adultos mayores. Lo que sí es coincidentes es que se ve una disminución de la votación de los jóvenes para las elecciones de 2009 y 2014; pero se incrementa la votación de los maduros y adultos mayores para estos mismos periodos.

La pregunta que surge es qué está motivando la disminución de la votación de los jóvenes en cada elección a partir de 2009 y 2014 
Aunque se ha dado una apertura y motivación para que la juventud se integre a los procesos electorales, aunado a que la mayoría de la población es joven seguida de los maduros y adultos mayores, lo que puede estar limitando su votación sugerimos es la inestable inserción juvenil en la sociedad visibilizada en las dificultades de entrada al mercado laboral o a los servicios económicos y al poco interés del estado por mejorar sus condiciones socioeconómicas. Lo que sí es importante destacar es que se hace necesario observar y explicar más a fondo esta disminución de la votación de los jóvenes para los periodos 2009 y 2014.

\begin{tabular}{|l|l|l|l|}
\hline Tabla $\mathrm{N}^{\circ} 4$ & \multicolumn{2}{|l|}{} \\
\hline Correlación de participación electoral y crecimiento económico \\
\hline Participación & Crecimiento 2004 & $\begin{array}{l}\text { Crecimiento } \\
2009\end{array}$ & Crecimiento 2014 \\
\hline 2004 & 0.867 & & \\
\hline 2009 & & 0.833 & \\
\hline 2014 & & & 0.683 \\
\hline
\end{tabular}

Fuente: Contraloría General de la República y Ministerio de Economía y Finanzas. Datos correlacionados de las variables de la base de datos creada y el cuadro por los investigadores para este trabajo.

Ya se tiene claro que cuando hemos cruzado crecimiento económico y participación electoral, el cruce hecho en las provincias que hemos analizado, nos indica que existe una relación entre la participación y crecimiento para los años 2004 y 2009, no fue así para el año 2014 en el cual la correlación baja hasta 0.683 . La pregunta que sigue es por qué si hemos visto que del 2004 al 2009, el crecimiento económico se incrementó un 43.64\%, y el intervalo entre el 2009 y el 2014 experimentó un incremento del 79.9\%, Si se analiza esto y se entiende que la política económica en el último periodo fue distinta a la del periodo anterior, podemos sugerir que la bonanza económica en el último periodo (2009-2014) produjo una disminución en la participación electoral del año 2014. Es decir, que cuando hay crisis económica o una política, cuyo crecimiento no se distribuye en las masas, la conciencia de cambio en la población produce una mayor participación electoral que cuando en el último periodo la bonanza económica permitió una reducción en la participación electoral. Esto es interesante y debatible y objeto de una investigación de mayor detalle y profundidad.

\begin{tabular}{|l|l|l|l|}
\hline Tabla N'5 \\
\hline Correlación de abstencionismo y crecimiento económico \\
\hline Abstencionismo & $\begin{array}{l}\text { Crecimiento } \\
\text { Económico 2004 }\end{array}$ & $\begin{array}{l}\text { Crecimiento } \\
\text { Económico 2009 }\end{array}$ & $\begin{array}{l}\text { Crecimiento } \\
\text { Económico 2014 }\end{array}$ \\
\hline
\end{tabular}




\begin{tabular}{|l|l|l|l|}
2004 & 0.992 & & \\
\hline 2009 & & 0.990 & \\
\hline 2014 & & & 0.990 \\
\hline
\end{tabular}

Fuente: Contraloría General de la República y Ministerio de Economía y Finanzas. Datos correlacionados de las variables de la base de datos y cuadro creado por los investigadores para este trabajo.

La lectura de esta correlación nos indica que existe una fuerte relación entre abstencionismo y crecimiento económico para los periodos 2004-2009-2014. Sugerimos que a mayor crecimiento económico aumenta el abstencionismo de manera gradual; pero constante, lo que puede entenderse como un comportamiento vinculado a la relación entre el acceso de los ciudadanos y ciudadanas a mayor ingreso económico directo; no obstante, al mismo tiempo al acceso de menos servicios básicos, esto podría profundizarse a partir de estudios desde la lógica del desarrollo humano y las visiones en el imaginario panameño respecto a la educación, salud, vivienda; como también los aspectos institucionales que favorecen la condiciones para acceder al ejercicio del sufragio. Harry Brown Araúz en el texto titulado: Siete paradojas de los imaginarios panameños sobre la democracia y sus instituciones, plantea una primera paradoja titulada "Aspiraciones democráticas versus individualismo intenso", en ella Araúz cita el Informe Nacional de Desarrollo Humano 2007-2008, y retoma en el siguiente sentido:

El Informe Nacional de Desarrollo Humano 2007-2008 revela profunda incongruencia entre las aspiraciones de la ciudadanía panameña y los métodos con que pretendemos alcanzarlos. El informe señala la preferencia que tiene la ciudadanía panameña por objetivos "deseables" y que evidentemente tienen un cariz universal y colectivo de generar consenso sobre las normas básicas del país, lograr legitimidad del sistema político y desarrollar políticas públicas equitativas, sin embargo, al plantearse la acción política se aceptan y practican conductas particulares, clientelistas y el control de los recursos públicos para el beneficio personal. Según el documento, "el deber ser" y "el ser" están disociados y se contradicen en todos los ámbitos. Dando un paso más allá de las nociones del "deber ser", siempre problemáticas por las implicaciones que tiene que definir y quién y cómo se establece "lo debido", se puede decir que las panameñas y panameños tenemos objetivos cuya naturaleza implica plantearse proyectos de índole colectiva $y$, por lo tanto procesados democráticamente, pero las vías con las que buscamos alcanzarlos son radicalmente individualistas y verticales. La frustración producida por semejantes incongruencia entre objetivos y método solo es comparable con la que produciría hundir un clavo golpeándolo con un zapato (Araúz).

Lo anterior nos lleva a pensar si el sostenido abstencionismo puede ser una vía para mostrar el descontento de las panameñas y panameños respectos a las necesidades colectivas no resueltas o no hay opciones respecto a las propuesta presentadas. 


\section{CONCLUSIONES Y POSIBLES PREGUNTAS PARA EL FUTURO}

- Según la hipótesis planteada en esta investigación, "el crecimiento económico determina la participación electoral y el abstencionismo en las tres (3) últimas elecciones generales de 2004-2009- 2014”, esta no se aleja de la realidad teórica planteada por Marx y Engels, cuando interpretan al estado y al poder como instrumento básico de dominación en la sociedad, cuando este, el estado, representa a la clase poderosamente económica y política de un país.

- Los resultados de nuestra investigación reflejan que para los periodos 2004 y 2009, la participación electoral para presidente fue definida por el crecimiento económico, pero no fue el mismo resultado para el periodo 2014. Este hallazgo del 2014 abre el campo al debate y a la investigación más profunda.

- Harry Brown politólogo panameño, reflexiona sobre, que para los periodos indagados, la inclinación ideología del voto se mantuvo beneficiando a los partidos de centro y centro derecha, estos partidos políticos que representan al poder económico y político en nuestro país son los que mayor electores cuentan para votar.

- Los resultados de nuestra investigación son contraproducentes con respecto a que la variable edad es determinante en la participación electoral de los periodos en estudio, con lo que se plantea en la teoría cuando se dice que la participación electoral es baja en la edad juvenil, alta en la madura y baja en la tercera edad. Los análisis nos llevan a concluir que los jóvenes son la población que más vota para presidente en los citados periodos, además de que se refleja una disminución de la participación sostenida para los periodos del estudio. Sugerimos que esta lectura se debe a la inestable inserción juvenil a la sociedad visibilizada en las dificultades de entrada al mercado laboral, a los servicios económicos y al poco interés del estado en mejorar sus condiciones socioeconómicas. Ante esta realidad, abrimos el compás al debate y a la pregunta por qué en nuestro país la población juvenil es la que más vota para elecciones presidenciales

- A pesar de que la mujer tiene grandes limitaciones para ejercer el voto por el hecho de ser mujer, en nuestro país, es ella la que más vota para los comicios electorales para presidente. Esta lectura también es contraproducente y conducente con la teoría actual que nos habla de que a mayor o menor integración de los grupos sociales depende la 
participación política y electoral. Sugerimos que estos resultados pueden explicarse no solo porque la pirámide poblacional nos indica que hay más mujeres que hombres en nuestro país: $52 \%$ mujeres y $48 \%$ hombres, también puede explicarse, porque la mujer está integrada en la mayoría al sistema educativo del país y se hacen ingentes esfuerzos por el sistema de partidos políticos y del Tribunal Electoral en integrar más y dar facilidades para que la mujer de nuestro país participe política y electoralmente.

- El crecimiento económico no siempre va a determinar la participación electoral, es decir, la bonanza no siempre convence a los electores a votar confluyen diversidad de factores que inciden en la intención de votar; quedó demostrado en la tabla $\mathrm{N}^{\circ} 4$, lo que orienta esta realidad es a profundizar en los estudios para conocer la verdad y establecer estrategias y políticas que permitan fortalecer la conciencia crítica de los electores.

\section{Referencias}

Araúz, H. B. (2018). El vencedor no aparece en la papeleta. Panamá: Descarriada.

Araúz, H. B. (s.f.). Siete paradojas de los imaginarios panameños sobre la democracia y sus instituciones . En T. E. Panamá, Reflexiones en un Panamá Democrático (págs. 77-93). Panamá.

Corporación Latinobarómetro . (2017). Latinobarómetro. Buenos Aires, Argentina.

Brown, H. (2009). Partidos Políticos y Elecciones en Panamá. Panamá.

Económico, O. p. (2017). Caminos de Desarrollo. Estudio Multidimensional de Panamá. Panamá : OCDE.

Electoral., O. d. (2015). Estudio sobre participación electoral en América Central. Washington, DC. USA: OEA.

Engels, F. (1974). El origen de la familia, la propiedad privada y el Estado. Moscú: Progreso.

Estado de la Región . (2016). Quinto Informe Estado de la Región en Desarrollo Humano Sostenible. San José, Costa Rica.

Finanzas, M. d. (2004-2009-2014). Actualización de las Líneas de Pobreza. Panamá: MEF.

Flores, B. F. (2009). Aproximación teórico-conceptual de la participación electoral: una discusión aún abierta. Desafíos, 77-95.

Nohlen, D. (2003). Ampliación de la participación política y reducción del abstencionismo: ejes de una cultura democrática y una nueva ciudadanía para el siglo XXI. XVII Conferencia Protocolo de Tikal, (págs. 1-14). San José Costa Rica.

OCDE. (2017). Estudio multidimensional Panamá Vol. 1. Caminos de Desarrollo, 15. 
República, C. G. (2004, 2009, 2014). Producto interno bruto. Panamá: Contraloría General de la República.

Romero., F. G. (2015). Estudio sobre participación electoral en América Central. Washington, DC. USA: OEA.

Secretaría General de la Organización de los Estados Americanos (SG/OEA) y la Universidad Laval. (2015). Estudio sobre Participación Electoral en América Central. Washington, DC : Departamento para la Cooperación y Observación Electoral de la Organización de los Estados Americanos, DECO/OEA, y Departamento de Sustentabilidad Democrática y Misiones Especiales de la Organización de los Estados Americanos, DSDME/OEA. .

Shumpeter, J. A. (1942). Capitalism,Socialism and Democracy, Harper and Row, Nuw York. New York.

Tribunal Electoral de Panamá. (2009-2014). Memoria técnica elecciones . Panamá.

Tribunal Electoral de Panamá. (2018). Relatoría del Encuentro Latinoamericano de Estudios Democráticos. Panamá.

Tribunal Electoral de Panamá. (s.f.). Memoria Técnica Elecciones 2014. Panamá.

Weber, M. (1971). Economía y Sociedad. Alemania: Ciencias Sociales. 